\title{
Demographics of Kenyan dentists under the predevolved system of government; a dental workforce study.
}

${ }^{1}$ Okumu B. A., ${ }^{2}$ Catherine L. M., ${ }^{3}$ Estie K., ${ }^{3}$ Marc T.

1Department of Oral Maxillofacial Surgery, Oral Medicine and Pathology, Oral Radiology, School of Dentistry, Moi University. Eldoret, Kenya.

2Department of Dentistry, School of Health Sciences, College of Health Sciences, Makerere University. Kampala, Uganda. Email: mcathy5k@gmail.com

${ }^{3}$ Faculty of Science, School of Human Science, Co-director International Research Collaborative - Oral Health and Equity (IRCOHE). The University of Western Australia (M309), 35 Stirling Highway,6009 Perth.

\begin{abstract}
Objective: The main aim of this study was to analyse the dental workforce in Kenya prior to the decentralization of health workforce management to county governments in 2013.

Methods: This was a cross-sectional study of Kenyan dentists who were practising as at 2013. Demographic data was obtained from the Kenya Medical Practitioners and Dentists' Board and the Ministry of Health annual retention registers. These data were integrated and analysed in Microsoft Excel 2016. All tests for significance were set at $95 \%$ confidence level $(\mathrm{p} \leq 0.05)$.

Results: Most of the dentists studied were male $(55.6 \%)$ and more than half $(54.5 \%)$ were below the age of 40 years $(\mathrm{M}=39.8, \mathrm{SD}=11.9)$. A majority $(79.3 \%)$ were general practitioners and approximately half $(50.8 \%)$ were involved in private practice. Whereas, $76 \%$ had received local undergraduate training, many specialists (51.2\%) held foreign degrees.

Conclusion: There is urgent need for Kenya to develop strategies that will increase and retain the number of dentists and specialists. It remains to be seen whether the creation of a decentralised system of government will address existing shortages as well as the age, gender and speciality imbalances affecting the dental workforce.
\end{abstract}

Key words: Kenya, dentists, dental specialists, demographics, pre-devolution.

INTRODUCTION: Human resources for health is one of the major issues of concern in healthcare service provision globally. Kenya happens to be among the 36 sub-Saharan Africa countries experiencing severe shortages of health personnel ${ }^{1}$. Based on government reports, the country is currently surviving on 20 physicians for every 100,000 people with several areas experiencing critical levels of geographical, gender and skill mix maldistribution ${ }^{2}$. The bulk of these health workers are heavily concentrated in urban areas where only a third of the population reside. Consequently, rural poor and many peri-urban dwellers continue to be the victims of maldistribution and inaccessibility of health services.

Correspondence: Okumu B.A.

Department of Oral Maxillofacial Surgery, Oral Medicine and Pathology, Oral Radiology,

School of Dentistry, Moi University.

P.O. Box 4606-30100 Eldoret, Kenya.

Telephone: +254724481635

Email: okumudr@gmail.com

Received: 05/11/2018

Accepted:14/05/2019

https://dx.doi.org/10.4314/ajoh.v9i1.2
Dentists, Community Oral Health Officers and Dental Technologists are the three main cadres of the oral health workforce in Kenya. Out of the three, dentists are the primary oral health care providers. The Kenya Medical Practitioners and Dentists Board (KMPDB), the official body mandated to regulate the training, registration and practice of medicine and dentistry in Kenya reports that just over 1000 dentists are registered ${ }^{24}$, translating to 1 dentist per 42,000 Kenyans. Most (80\%) of these are located in the big cities and towns where only $10 \%$ of the population can access treatment ${ }^{5,6}$. Although there are no studies evaluating the characteristics of the dental workforce, it is believed that many dentists are in private practice, especially the relatively small specialist workforce which is also known to offer consultant services in referral hospitals and/or teaching institutions. A few others, usually with a Master of Public Health degree or related qualifications, are in administrative roles at the Ministry of Health and other public health institutions.

The aim of this study was to analyze the supply and demographic characteristics of the dentists' population in pre-devolved Kenya. These findings 
will hopefully inform workforce planning and policy development in oral health care service delivery in the current devolution era.

\section{METHODS}

This was a descriptive cross-sectional study involving dental practitioners in Kenya as at 2013. The main workforce data was directly obtained with written permission from the Kenya Medical Practitioners and Dentists Board (KMPDB), as well as the Ministry of Health.

Dentists met the inclusion criteria if they were practicing as at 2013. This included all those listed in the 2013 Ministry of Health register and/or those listed in the KMPDB retention registers of 2014-16 (medicalboard.co.ke/online-services/retention/) but whose year of registration was 2012 or earlier. The two registers were used to form an integrated database for this study; dentists on internship or who graduated in 2013 were excluded.

For both data collation and statistical analysis, data were systematically entered in Excel (Version 2016 Microsoft, Redmount USA). The variables analysed included the gender; age; year of the first qualification; country of training; the level of training; speciality and sector (private or public) of practice. Where certain variables were missing, and this was identified, statistical analysis was adjusted on a variable-by-variable basis to accommodate these missing data elements. For instance, age data was only available and analysed for 674 out of the 737 dentists included in this study. All tests for significance were set at $95 \%$ confidence level ( $p \leq 0.05$ ).

\section{RESULTS}

In total, 737 out of the estimated 1000 registered dentists in 2013 (approximately three quarters) were included in the integrated register.

Gender and Age: The number of dental practitioners qualifying annually has increased from just 6 in the 1970 s to about 270 in the period between 2000 to 2009. Out of the 737 dentists included in this study, 410 (55.6\%) were male and $327(44.4 \%)$ were female. Despite the overall higher proportion of males, the results show that the percentage of male dentists visa-vis that of females graduating every year has gradually declined; from an average of $88.2 \%$ in the 70 s to $58 \%$ in the 1990 s $^{9}$. By the period between 2000 to 2009 , on average, slightly more females (51\%) than males (49\%) were graduating. A similar trend was evident among dentists qualifying with postgraduate studies; the number of females increased from zero percent in the 1970 s to $50 \%$ in the 2000 s and eventually surpassed that of males by $4.4 \%$ in the 2010 s. In terms of age, the mean overall age was 39.8 years $(n=674)$, with males being older $(\mathrm{M}=41.5, \mathrm{SD}=12.4)$ than females $(\mathrm{M}=37.7, \mathrm{SD}=10.9)$ ( $\mathrm{t}$ test=4.130, $\mathrm{P}<0.05)$. There was an increasing number of female dentists with decreasing age.

(Table 1).

Training: The majority of the 737 dentists had only an undergraduate degree $(79.3 \%, n=585)$, while $18.5 \%$ and $2.2 \%$ had second and third degrees respectively. Although most of the Bachelor of Dental Surgery (BDS) degrees were acquired in local universities $(76 \%)$, a significant proportion $(24 \%)$ held foreign degrees, with the most common overseas destinations ${ }^{10}$ being India (10.4\%) and UK (3.4\%). More than half $(54.8 \%)$ of those with postgraduate degrees trained abroad, predominantly in the UK $(29.5 \%)$, South Africa (7.5\%), and the USA (6.2\%). However, there has been a downward trend in overseas training since the 1990s. (Fig. 1 illustrates the postgraduate trends based on the country of training)

Dental Specialists: A total of 138 dental and nondental specialists were identified with at least 2 dentists having more than one area of specialisation. Of these, the largest speciality group was Public Health (24\%), followed by Oral Maxillofacial Surgery (21\%) and Paedodontics (15\%). Another 8\% and 9\% were Periodontists and Prosthetists respectively, while restorative specialists and orthodontists each made up $6 \%$ of the specialist workforce. There were five Oral Pathologists (4\%) and three Biomaterial specialists (2\%). Dental Public Health, Oral Maxillofacial Radiology (OMFR) and Endodontics each comprised $1 \%$ or less of the dental specialist workforce. From the results, dental specialists had a mean age of 46.4 years $(\mathrm{n}=136, \mathrm{SD}=9.1)$, which was significantly higher than that of the entire dentist population (39.8 years) $\mathrm{P}<0.05$ ) ( $\mathrm{t}$ test $=8.386, \mathrm{P}<0.05)$. There was also a greater number of male specialists (57\%) compared to females (43\%). Although females comprised most Public Health specialists (63.6\%), Paedodontists (67\%) and Biomaterials specialists $(100 \%)$, most of the other fields including Oral Maxillofacial Surgery (80\%), Periodontology (82\%), Orthodontics (75\%) and Prosthetics (61. 5\%) were male dominated. (Table 2 shows a summary of the age distribution and mean 
Table 1: The distribution of dentists by Age group and gender

\begin{tabular}{|l|c|c|c|}
\hline AGE(YRS) & $\begin{array}{c}\text { Female } \\
\mathbf{n}(\mathbf{\%})\end{array}$ & $\begin{array}{c}\text { Male } \\
\mathbf{n}(\mathbf{\%})\end{array}$ & $\begin{array}{c}\text { ALL } \\
\mathbf{n}(\mathbf{\%})\end{array}$ \\
\hline $20-29$ & $89(55.3)$ & $72(44.7)$ & $\mathbf{1 6 1}(\mathbf{2 3 . 8 )}$ \\
\hline $30-39$ & $89(43)$ & $118(57)$ & $\mathbf{2 0 7}(\mathbf{3 0 . 7 )}$ \\
\hline $40-49$ & $72(45.6)$ & $86(54.4)$ & $\mathbf{1 5 8 ( 2 3 . 4 )}$ \\
\hline $50-59$ & $42(42)$ & $58(58)$ & $\mathbf{1 0 0 ( 1 4 . 8 )}$ \\
\hline $60-69$ & $7(16.7)$ & $35(83.3)$ & $\mathbf{4 2}(\mathbf{6 . 2})$ \\
\hline $70-79$ & $2(33.3)$ & $4(66.7)$ & $\mathbf{6 ( 0 . 9 )}$ \\
\hline Total & $\mathbf{3 0 1 ( 4 4 . 7 )}$ & $\mathbf{3 7 3 ( 5 5 . 3 )}$ & $\mathbf{6 7 4}(\mathbf{1 0 0})$ \\
\hline
\end{tabular}

Table: 2. Age distribution of dentists in each specialty

\begin{tabular}{|c|c|c|c|c|c|c|c|}
\hline \multirow[b]{2}{*}{ SPECIALITY } & \multicolumn{5}{|c|}{ AGE (YRS) } & \multirow[b]{2}{*}{$\operatorname{ALL}(n)$} & \multirow{2}{*}{$\begin{array}{c}\text { MEAN } \\
\text { AGE(YRS.) }\end{array}$} \\
\hline & $30-39$ & $40-49$ & $50-59$ & $60-69$ & $70-79$ & & \\
\hline SURGERY & 6 & 14 & 4 & 5 & 1 & 30 & 48.1 \\
\hline ORAL PATHOLOGY & 2 & 1 & 0 & 2 & 0 & 5 & 48 \\
\hline ORTHODONTICS & 0 & 6 & 2 & 0 & 0 & 8 & 47.6 \\
\hline PAEDODONTICS & 8 & 7 & 4 & 2 & 0 & 21 & 44 \\
\hline PERIODONTOLOGY & 3 & 4 & 3 & 1 & 0 & 11 & 45.6 \\
\hline PROSTHETICS & 6 & 4 & 0 & 2 & 0 & 12 & 43.8 \\
\hline PUBLIC HEALTH/DPH & 4 & 18 & 9 & 2 & 0 & 31 & 53.4 \\
\hline RESTORATIVE & 2 & 3 & 2 & 1 & 0 & 8 & 47.5 \\
\hline BIOMATERIALS & 2 & 1 & 0 & 0 & 0 & 3 & 38 \\
\hline OTHER* & 0 & 1 & 1 & 2 & 0 & 4 & 49.8 \\
\hline ALL n (\%) & $33(24.2)$ & $59(43.4)$ & $27(19.9)$ & $16(11.8)$ & $1(0.7)$ & $136(100)$ & $46.4(\mathrm{SD}=9.1)$ \\
\hline
\end{tabular}

* Other represents specialists in Cytology (n=2), Endodontics (n=1) and Maxillofacial Radiology (n=1) 
Table 3: The Distribution of Dental Specialists by Gender

\begin{tabular}{|l|r|r|r|}
\hline SPECIALITY & $\mathbf{M}$ & $\mathbf{F}$ & ALL \\
\hline BIOMATERIALS & 0 & 3 & 3 \\
\hline CYTOLOGY & 2 & 0 & 2 \\
\hline DENTAL PUBLIC HEALTH & 2 & 0 & 2 \\
\hline ENDODONTICS & 1 & 0 & 1 \\
\hline HUMAN NUTRITION & 0 & 1 & 1 \\
\hline MAXILLOFACIAL RADIOLOGY & 1 & 0 & 1 \\
\hline ORAL/MAXILLOFACIAL SURG. & 24 & 6 & 30 \\
\hline ORAL PATHOLOGY & 3 & 2 & 5 \\
\hline ORTHODONTICS & 6 & 2 & 8 \\
\hline PAEDODONTICS & 7 & 14 & 21 \\
\hline PERIODONTOLOGY & 9 & 2 & 11 \\
\hline PROSTHETICS/PROSTHODONTICS & 8 & 5 & 13 \\
\hline PUBLIC HEALTH & 12 & 21 & 33 \\
\hline RESTORATIVE & 5 & 4 & 9 \\
\hline Total & $\mathbf{8 0}$ & $\mathbf{6 0}$ & $\mathbf{1 4 0}$ \\
\hline
\end{tabular}

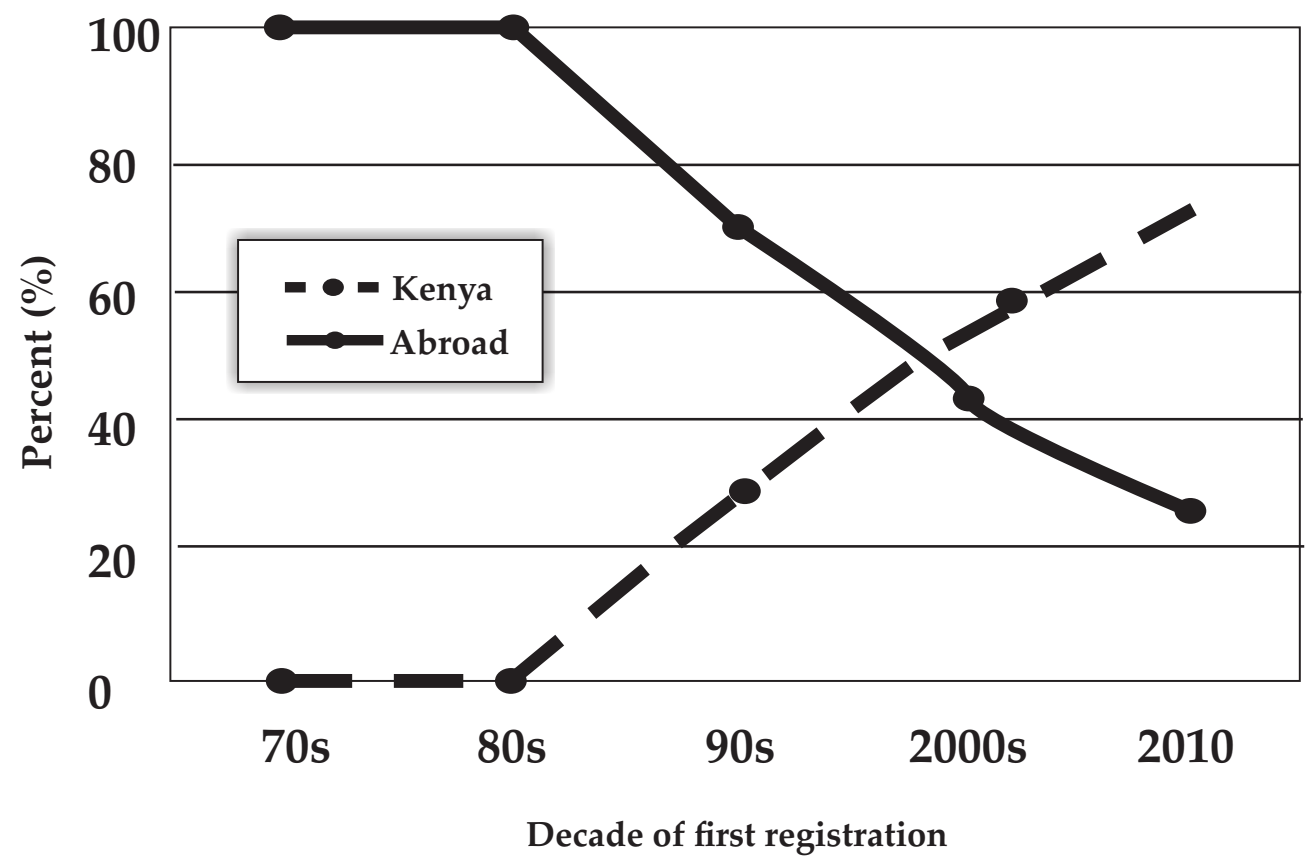

Figure 1. Local versus Overseas Postgraduate (Diplomas, Masters and PhD) Training Trends. 


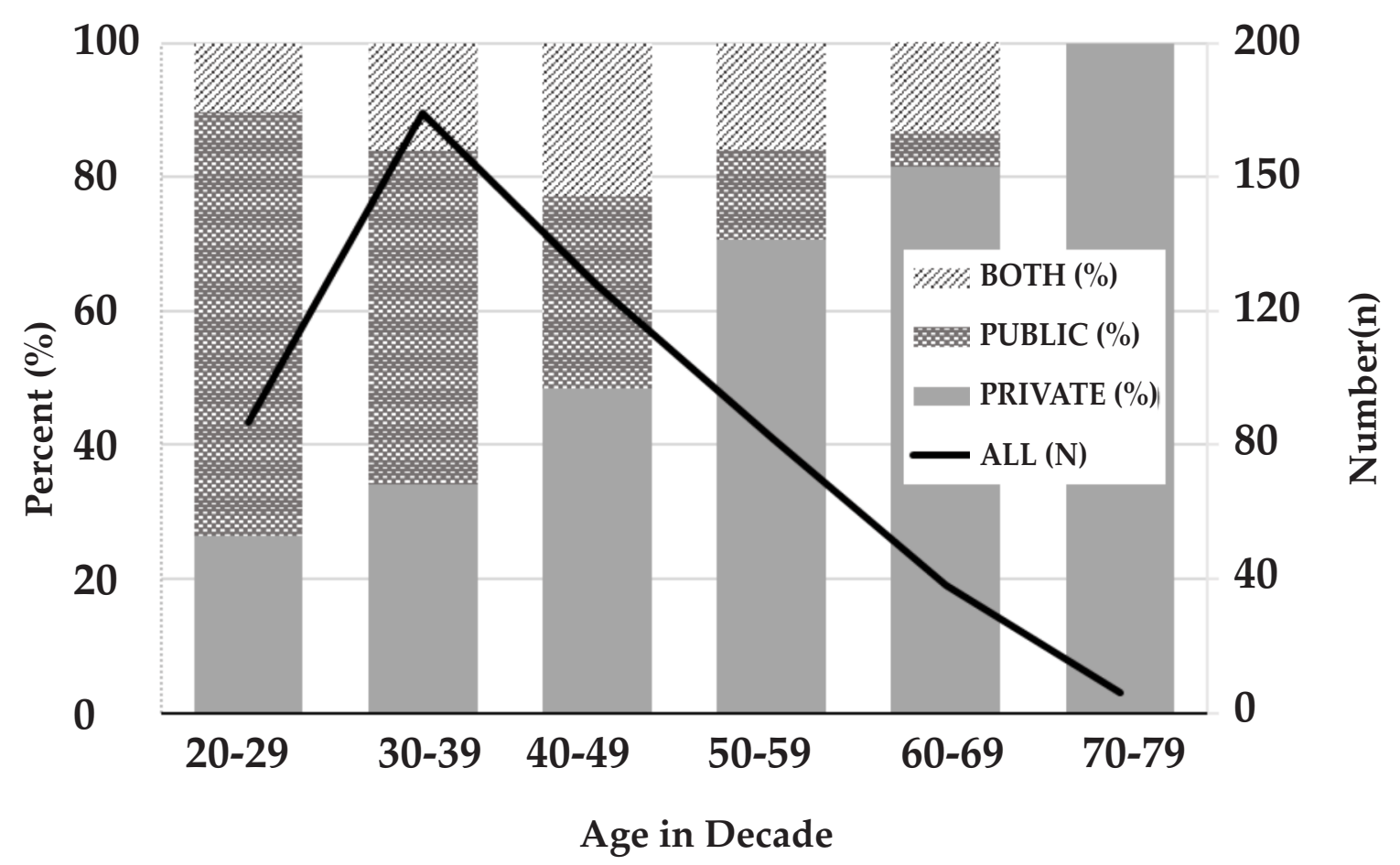

Figure 2. Dentists in the Different Sectors by Age Groups

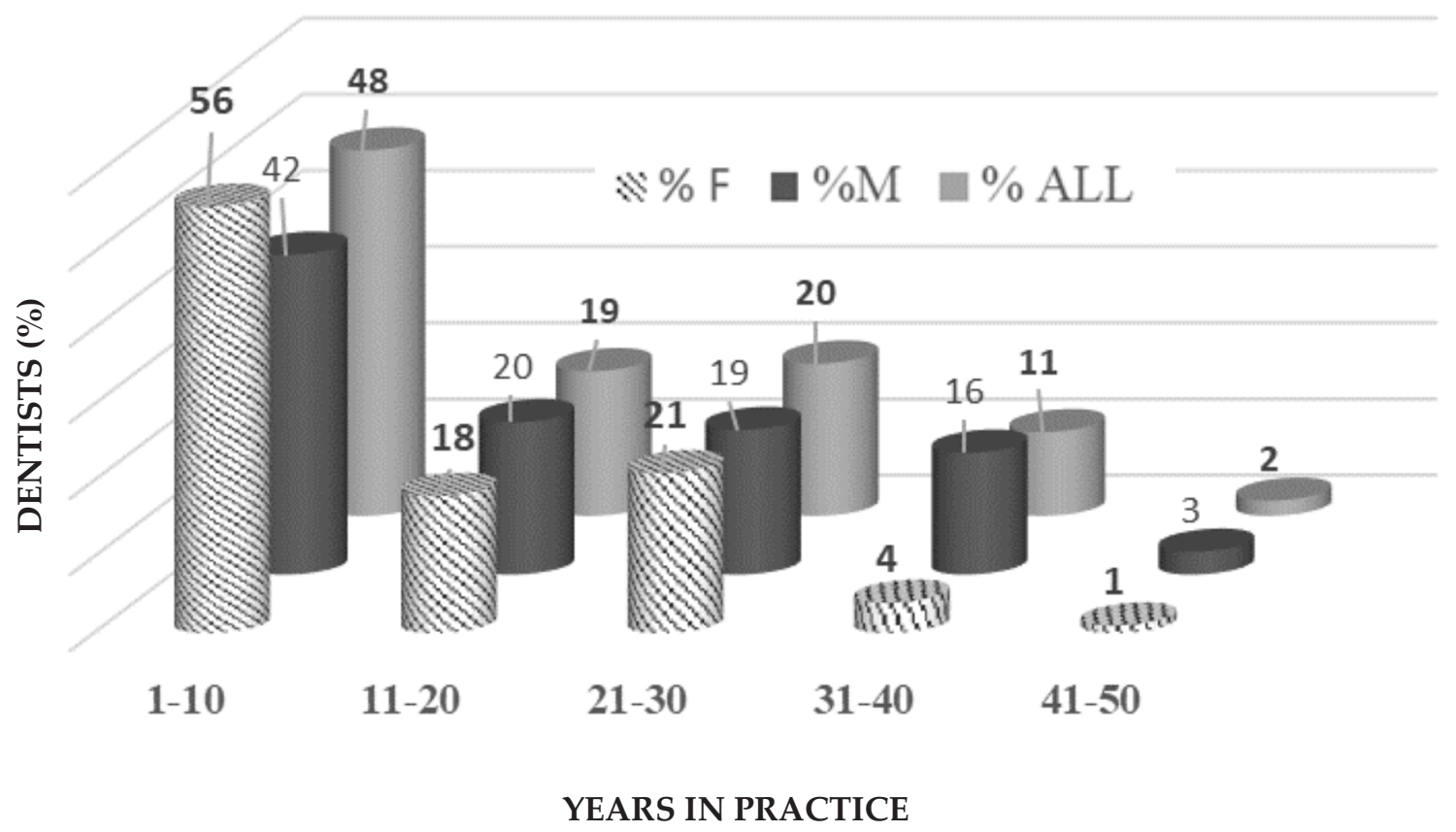

Figure 3. Years in Practice by Gender 
age in each speciality.)

By training, more than half of dental specialists (51.2\%) qualified in foreign countries, predominantly in the UK (35.3\%). Most of the Oral Maxillofacial surgeons (61\%), Paedodontists (76\%), and Public Health specialists $(74 \%)$ trained locally, whereas no specialist in Oral Pathology, Biomaterials, DPH, Endodontics, Radiology, Orthodontics and Restorative dentistry trained in Kenya.

Practice characteristics: From this study, $43.4 \%$ and $41.6 \%$ of all active dentists $(n=560)$ were solely in the private sector and public sector respectively. The remaining $15 \%$ were practising in both sectors simultaneously. On the other hand, a larger majority of the specialist dental workforce $(71 \%, \mathrm{n}=94)$ were in either part-time $(52 \%)$ or full-time $(48 \%)$ private practice compared to only $29 \%$ in the public sector. In terms of gender, there was a higher percentage of male dentists in both public (54.1\%) and private $(61.6 \%)$ sectors but overall, the difference was not statistically significant (chi square test, $P>0.05$ ). The mean age of dentists in private sector (45.9yrs, SD=12.4) was significantly higher than of those in the public sector (34.6, $\mathrm{SD}=8.1$ ) (t test, $\mathrm{P}<0.05)$ Fig. 2 shows the age comparison by sector. Overall, close to half $(48 \%)$ of the dentists had practiced for 10 years or less with $16 \%$ of men having practiced for more than thirty years compared to only $4 \%$ of the women. Fig. 3 illustrates the years of practice by gender.

\section{DISCUSSION}

The upward trend in the overall number of dentists is attributable to an increase in the number of dentists qualifying every year. Undoubtedly, the rising number of dentists could not have come at a better time considering the high levels of oral disease as reported by the recent Kenya National Oral Health Survey $(\mathrm{KNOHS})^{3}$. However, the overall growth has slowed down to just $5 \%$ annually and is yet to measure up with the present population oral health needs and the rapidly shifting population demographics. Currently, the estimated dentist to population ratio of $1: 40,000$ is well above the African average of 1: 150,000, but it is still way below that of industrialised countries (1: 2000) and the WHO minimum recommendation of 1 : $7000^{5,6}$. As the number of dentists increases, it appears the gap between male and female practitioners has also been reducing. The present analysis has revealed that even though the profession is still maledominated, there are a lot more Kenyan women taking up dentistry. Similar findings have been reported in several countries across different economic divide. In Nigeria, as at 2000, gender imbalances were found to be normalising and a complete balance was expected by 2015 , while in the UK, it has been projected that females will make up more than half of the dentists by the year $2020^{8,9}$. In a few countries such as Romania, female dentists significantly outnumber their male colleagues $^{10}$.

The feminisation of dentistry has come with several implications ${ }^{11}$. For instance, women are more likely to work part-time, take longer career breaks to care for their families, handle less workload and are less endeared towards taking leadership positions compared to their male colleagues ${ }^{12-14}$. Further investigations to determine these gender differences in Kenya and their impact on dental practice need to be undertaken. Based on the age analysis, it appears that there is a rise is the number of youthful dentists in Kenya. This implies that the country is unlikely to experience shortages due to aging as has been the case in many industrialised states ${ }^{15-17}$. However, appropriate policies to retain and increase the number of dentists still need to be implemented in order to mitigate shortages that may result from emigrations, change of professions, early retirement and death, among others. Kenya, like a vast majority of its developing counterparts, is still faced with an acute scarcity of specialists across all dental fields ${ }^{18}$. This is a pervasive problem affecting countries across the economic divide. In most of Europe, most dentists remain generalists with little or no postgraduate education and certain countries in the European Union (EU) have no official dental speciality; instead, dentists rely on continuous education and short courses to acquire specialised skills ${ }^{19,20}$. Similarly, recent data indicate that up to $90 \%$ of dentists in Australia, 83\% in Hong Kong and 76\% in Shanghai, China are general practitioners ${ }^{21-23}$. This phenomenon has been attributed to different factors. In one London study, where more than $80 \%$ of the respondents admitted that they would continue in general practice, time constraints, high costs, disruption of life, stringent requirements, and lack of interest were observed as some of the barriers to specialist training ${ }^{24}$. For Kenya, further research is required to establish existing local barriers. Ultimately, the rise in untreated oral conditions among the Kenyan population can partly be attributed to the limited access to specialist care. In a profession that has been largely commercialised worldwide, dentists who choose to specialise are increasingly preferring the 
seemingly more lucrative clinical fields such as Orthodontics and Oral Surgery to Preventive dentistry $^{21,25}$. This has grossly impeded efforts towards achieving primary health care as a means for ensuring health for all. The relationship between gender and the choice of speciality was equally evident in the current findings. Male dentists continue to heavily dominate the majority of the speciality areas particularly OMFS, Orthodontics and Periodontology, while their female colleagues only dominated in Public health and Paediatric dentistry. These findings are comparable to those of a previous Kenyan study in which female medical students had a 5 -fold chance of choosing Paediatrics due totheir unique ability to handle children and were generally more disposed to choose controllable lifestyle specialities such as Public Health than their male compatriots ${ }^{26}$. Similar findings have been demonstrated among dental specialists in Australiaa, the $\mathrm{UK}^{27}$, the USA ${ }^{28}$, and Puerto Rico ${ }^{29}$ among others. These unique qualities, if harnessed, can be valuable in enhancing primary oral health care, particularly among children. As regards the training of dentists and dental specialists, a third of the undergraduate degrees and more than half of the postgraduate degrees were acquired overseas. This compares well with Australia where in 2013, 25\% of employed dentist had obtained their first degree $\operatorname{abroad}^{30}$. In the USA, just like in Kenya, most of foreign-trained dentists qualified in India in the period between $2002-2005^{31}$. Fortunately for Kenya, there is a gradual decline in foreign training. Despite the fact that overseas training offers international medical experiences that have many potential benefits to the individual and home country ${ }^{32}$, it poses a huge financial burden and is beyond the reach of many in a lower-middle income country like Kenya. This is further aggravated by the fact that scholarships in dentistry, compared to many other non-clinical courses, are limited. Additionally, studies have shown that foreign-trained doctors are likely to work abroad or practice in bigger cities in search of better financial rewards and career development opportunities; a trend that only complicates the existing shortages and maldistribution of dentists in the country. There is need for Kenya to introduce more postgraduate programs that will attract both local and international applicants.

The study also established that Kenyan dentists are more likely to work in the private than public sector, with a distinct gender and age differences between the sectors. Female dentists were more likely to work in the public sector than their male counterparts, with a majority working as full-time employees of the Ministry of Health. Studies have shown women prefer the public sector due to the more flexible nature of work and are less likely than men to establish their own practice ${ }^{13,14}$. Similarly, younger dentists dominated the public sector but as they become older with more experience and financial stability, they are likely to establish their own private practices, preferably in urban areas for better financial rewards and career satisfaction. Generally, the inadequate numbers of dentists in the public sector, coupled with the gender and age imbalances implies that most Kenyans, who heavily rely on the more affordable public services are greatly disadvantaged. This is especially true when it comes to accessing specialised dental care in rural and remote areas. There is, therefore, a great need for the government to offer more incentives if it is to retain dentists across all age groups within the public sector.

\section{CONCLUSION}

The findings of this study indicate a rise in dental workforce numbers, but a dentist-to-population ration still below $\mathrm{WHO}$ recommendations, a scarcity of specialists, and an existing age, gender and speciality maldistribution across Kenya. These findings should spur discussions on the role of women in dentistry and the importance of continuous dental workforce surveillance in mitigating existing and future inadequacies. It is recommended that some of these issues be addressed through the training, deployment, and retention of a gender-balanced, equally distributed dental workforce with adequate skill-mix. Additional qualitative research is needed if appropriate dental workforce strategies are to be implemented.

\section{ACKNOWLEDGMENTS}

The authors would like to acknowledge the following for their contribution towards this study: The CEO of the Kenya Medical Practitioners and Dentists board, Daniel Yumbya and Ministry of Health for providing general data on registered dentists. Secondly, Dr Maureen Ochieng who helped collect data from individual dentists at the School of Dentistry and Dr Mulupi for giving additional information on dental workforce at the Moi Teaching and Referral Hospital. This work was fully funded by the primary author. 


\section{REFERENCES}

1. WHO. Working together for health:The World Health Report 2006. Geneva,Switzerland.

2. Ministry of Health. Health Sector Human Resources Strategy 2014-2018. Kenya; 2014.

3. Ministry of Health. The Kenya Nationa Oral Health Survey Report 2015.

4. Kenya Medical Practitioners and Dentists Board. Doctors' Retention Register [Available from:http://medicalboard.co.ke/onlineservices/retention/

.5. Siringi S. Kenya embarks on campaign to improve oral health. The Lancet. 2002;360(9336):856.

6. Daily Nation. Dental diseases affect about nine in 10 adults - survey Kenya2016 [Available from:http://www.nation.co.ke/news/kenyasuffers-from-acute-shortage-of-dentists-meettold/-/1056/3131198/-/ce49mcz/-/index.html.

7. Kenya National Bureau of Statistics. Kenya Facts and Figures 2014. 2014.

8. Ogunbodede EO. Gender Distribution of Dentists in Nigeria, 1981 to 2000. J Dent Educ. 2004;68(7 suppl):15-8.

9. Murray JJ. Better opportunities for women dentists: a review of the contribution of women dentists to the workforce. British Dental Journal. 2002;192(4):191-6.

10. Oancea R, Amariei C, Eaton KA, Widström E. The healthcare system and the provision of oral healthcare in European Union member states: Part 5: Romania. British dental journal. 2016;220(7):361.

11. McKay JC, Quiñonez CR. The Feminization of Dentistry: Implications for the Profession. Journal of the Canadian Dental Association. 2012;78:1-6.

12. Newton JT, Thorogood N, Gibbons DE. The work patterns of male and female dental practitioners in the United Kingdom. International Dental Journal. 2000;50(2):61-8.

13. Murphy TC, Parkin NA, Willmot DR, Robinson PG. The feminisation of the orthodontic workforce. British Dental Journal. 2006;201(6):355.

14. Ayers KMS, Thomson WM, Rich AM, Newton JT. Gender differences in dentists working practices and job satisfaction. Journal of Dentistry. 2008;36(5):343-50.15. Chrisopoulos S. Trends in the Australian dental labour force, 2000 to 2009 : dental labour force collection, 2009. Nguyen T, Australian Institute of $\mathrm{H}$, Welfare, Australian Research Centre for Population Oral H, editors. Canberra: Canberra : Australian Institute of Health and Welfare; 2012.

16. Williams JN. The Aging Dental Workforce: Implications for the 21st Century. Annual Review of Gerontology \& Geriatrics. 2005;25:8997,R12.

17. Treasure E. Dental workforce issues in the United Kingdom. J Dent Educ. 2004;68(7):23-5.

18. Yamalik N, Ensaldo-Carrasco E, Cavalle E, Kell K. Oral health workforce planning part 2: figures, determinants and trends in a sample of World Dental Federation member countries. Int Dent J. 2014;64(3):117-26.

19. Gallagher JE, Eaton KA. Health workforce governance and oral health: Diversity and challenges in Europe. Health policy. 2015;119(12):1565-75.

20. Bravo M, Martín LS, Casals E, Eaton KA, Widström E. The healthcare system and the provision of oral healthcare in European Union member states. Part 2: Spain. British Dental Journal. 2015;219(11):547-51.

21. Australian Research Centre for Population Oral Health, The University of Adelaide South Australia. Dental specialists in Australia. Australian Dental Journal. 2010;55(1):96-100.

22. Chu C, Wong S, Suen R, Lo E. Oral health and dental care in Hong Kong. Surg J R Coll Surg Edinb Irel. 2013;11:153-7.

23. Gu Q, Lu Hx, Feng Xp. Status of the dental health care workforce in Shanghai, China. International Dental Journal. 2012;62(6):331-6.

24. Fisher NL, Wilson R, Bartlett D. The perceived barriers of vocational dental practitioners in London to specialisation. British Dental Journal. 2007;203(5):25-7.

25. Drugan CS, Chestnutt IG, Boyles JR. The current working patterns and future career aspirations of specialist trainees in dentistry. British Dental Journal. 2004;196(12):761.

26. Maseghe Mwachaka P, Thuo Mbugua E. Specialty preferences among medical students in a Kenyan university. The Pan African Medical Journal. 2010;5.

27. Hunter M, Harrhy L, Morgan M. The United Kingdom's specialist workforce in paediatric dentistry: current and future trends. British 
Dental Journal. 2010;208(12):559-62.

28. Lambert ME, Holmboe SE. The Relationship between Specialty Choice and Gender of U.S. Medical Students, 19902003. Academic Medicine. 2005;80(9):797-802.

29. Arévalo O, Saman DM, Tabares M, Sotomayor L, Hernández A. Pediatric dentistry workforce in Puerto Rico: Results of a 2011 survey. Puerto Rico Health Sciences Journal. 2013;32(1):18-24.

30. Australian Institute of Health and Welfare. Oral Health and Dental Care in Australia. 2019 [Available from:http//www.aihw.gov.au/ reports/dental-oral-health-and-dental-care-inaustralia/report-editions

31. Sweis LE, Guay AH. Foreign-trained dentists licensed in the United States: exploring their origins. Journal of the American Dental
Association (1939). 2007;138(2):219-24.

32. Thompson MJ, Huntington MK, Hunt DD, Pinsky LE, Brodie JJ. Educational Effects of International Health Electives on U.S. and Canadian Medical Students and Residents: A Literature Review. Academic Medicine. 2003;78(3):342-7.

33. Dossajee H, Obonyo N, Ahmed SM. Career preferences of final year medical students at a medical school in KenyaA cross sectional study. BMC medical education. 2016;16(1):1.

34. Willis-Shattuck M, Bidwell P, Thomas S, Wyness L, Blaauw D, Ditlopo P. Motivation and retention of health workers in developing countries: a systematic review. BMC Health Services Research. 2008;8(1):1-8. 